Computational Aspects of Nonlinear Fracture Mechanics

Authors:

W. Brocks

A. Cornec

I. Scheider 


\title{
Computational Aspects of Nonlinear Fracture Mechanics
}

\author{
W. BROCKS, A. CORNEC, and I. SCHEIDER \\ GKSS-Forschungszentrum, Geesthacht, Germany
}

This article was originally written in the form of a chapter in:

\author{
I. Milne, R. O. Ritchie, B. Karihaloo (Editors): Comprehensive Structural Integrity \\ Fracture of Materials from Nano to Macro \\ ISBN: 0-08-043749-4 (Set). \\ R. de Borst, H. A. Mang (Volume Editors): \\ Volume 3: Numerical and Computational Methods \\ ISBN 0-08-044158-0, pp. 127-209.
}

(c) Copyright 2003, Elsevier Ltd., All Rights Reserved.

Comprehensive Structural Integrity is a 10 volume reference work which covers all activities involved in the assurance of structural integrity. It provides engineers and scientists with an unparalleled depth of knowledge in the disciplines involved. The scope covers all industries and technologies, from the massive offshore structures to the miniscule biological structures, and includes consideration of heavy section structures, thin sheet structures, and structures at the nano scale. Volume 1 covers these issues in general, using examples and case studies to give practical examples of how the disciplines are applied. Volumes 2 to 6 address the underlying theories and methodologies, covering theoretical and computational methods, fatigue, environmental influences, and high temperature effects. Volume 7 covers practical failure assessment methods, and addresses the assessment of structures which contain crack-like defects. Volumes 8 and 9 cover in turn, interfacial and nano-scale failure and the treatment of structures engineered for bio-medical applications. Finally, a subject index is contained in volume 10 .

Comprehensive Structural Integrity provides a first point of entry to the literature for the both engineer and researcher across the whole field of structural integrity. In all there are 130 chapters with contributions from over 190 distinguished experts from 21 different countries. It is published by Elsevier, and this article is reprinted with the permission of Elsevier.

Information about Comprehensive Structural Integrity can be obtained from www.elsevier.com. 